\title{
The Metamorphosis And Bifurcation Of Guanxi In Virtual Third Spaces: The Role Of BBS In Changing Social Relationships In China
}

Peter L. Banfe, Ohio Northern University, USA

\begin{abstract}
This research is a the second installation of a planned series of articles exploring the dynamic interaction between the forces of modernization as represented by technology, specifically virtual forms of communication, and traditional culture in China. The focus of the research of this article is the phenomenon of the ubiquity and popularity of BBS (electronic bulletin board systems) in China, long considered "old school" and eclipsed by newer forms of virtual interaction in the West. The research explores the possibility that BBS's are developing into virtual third space in which we find traditional social constructs in China being challenged and modified in important ways. Specifically the research underlying this paper proposes to explore that hypothesis that an analysis of the interaction, operations and structure within these social spaces (BBS) might lead one to consider whether or not Guanxi, the relational glue which adheres Chinese society together, as well as other related cultural values and behaviors, are not being updated and modified in critical ways within these virtual third spaces. Additionally, the research proposes that Guanxi may be bifurcating within the virtual societies of the BBS, where the shared collective experiences of "social networking" of Guanxi has split from the "utilitarian reciprocal obligation" of "houmen" or guanxi practice. The results of the research tentatively confirm this proposition and identifies how the unique structure of BBSs and rules of interaction create a new virtual third space, or public sphere, which, while maintaining some aspects of traditional Confucian social order and Guanxi, are leading to their metamorphosis within these virtual communities.
\end{abstract}

Keywords: China; Guanxi; BBS; modernization; technology; culture; communication

\section{INTRODUCTION}

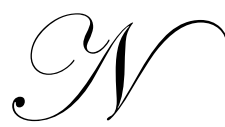

o one can stop talking about China. It is the world second largest economy, which passed up Japan in 2009 with a $\$ 4.9$ trillion GDP and a growth rate of a whopping 8.7\% (BBC, 2010). And what is remarkable is that rapid growth is projected to continue for decades to come. Some predict that the Chinese Economy will reach $\$ 123$ trillion by 2040, nearly three times the economic output of the entire world in 2000 (Foreign Policy, 2010). It contains the world's largest mass of people and consumes staggering amounts of the world's resources to feed its economy. Researchers at the Nomura Institute of Capital Markets Research project that China's will pass the US economy as the world's largest somewhere between 2026 and 2039 (Mathias, 2009). It is a country of incredible diversity and a rich history.

Although China can still be characterized as a repressive communist totalitarian regime, remarkably its economy is rapidly transitioning away from central planning and its government has been enthusiastically flirting with capitalism. The regime is attempting to harness the incredible power of markets in hopes of strengthening its legitimacy. As part of this plan, the government has embraced technology. During this economic crisis the government has poured 4 trillion yuan into infrastructure construction, which has promoted steady growth in 
network development (CNNIC, 2009). At the end of 2009 they completed phase three of the TD-SCDMA network coverage project. Investment in telecom assets in 2009 was up $28.5 \%$ over that in 2008 . The sheer size of China renders this transition and the embrace of technology of critical importance and of great interest to academics, whether they are political scientists, sociologists or economics. In addition, Western technology firms are lured by the vast opportunities of a hooked up online population in a country which currently already has, with less than $30 \%$ penetration, the world's largest online user base.

For China's current regime, Pandora may be escaping from the box. As the dizzying pace of change continues, China is being exposed in a dramatic way to the shocks of modernization. And one could argue that the Internet is leading the way, and accelerating that change as a virtual "third space" and nascent public sphere. And, to the chagrin of China's government, it is one in many ways out of their control. And as it does, traditional cultural values and antecedents are meeting head-on with the forces of modernization such as consumerism, individualism and capitalism. One might argue that the use of the Internet in China is both changing social streams of consciousness and ways of perceiving the world as well as is being changed by the power of Chinese culture. Certainly one could argue that the power of Apparatgeist is being mediated through the rich cultural filter of the Middle Kingdom (Katz, Aakhus, 2002, Katz, 2003, Katz, Aakhus, Kim \& Turner, 2003).

This research is a the second installation of a planned series of articles exploring the dynamic interaction between the forces of modernization as represented by technology, specifically virtual forms of communication, and traditional culture in China. This particular piece of research explores the possibility that BBS's are a virtual third space in which we find traditional social constructs in China being challenged and modified in important ways. Specifically the research underlying this paper proposes to explore the hypothesis that an analysis of the interaction, operations and structure within these social spaces (BBS) might lead one to consider whether or not Guanxi, the relational glue which binds Chinese society together as well as other related cultural values and behaviors, are not being updated and modified in critical ways within these virtual third spaces. Additionally, it explores whether Guanxi has bifurcated within the virtual societies of the BBS, where the shared collective experiences of "social networking" of Guanxi has split from the "utilitarian reciprocal obligation" of "houmen" and guanxi practice. A secondary question, beyond the scope of this research, is how this new virtual culture may spill over and lead to modification of real world norms of interaction within China.

\section{CULTURAL ANTECEDENTS: GUANXI, CONFUCIANISM, COLLECTIVISM, HIGH CONTEXT}

\section{Guanxi And Confucius}

Park and Luo (2001) define guanxi as an intricate, pervasive network of relations characterized by reciprocal obligation, assurances and understandings. Chen and Chen define guanxi as "an informal particularistic, personal connection between two individuals who are bounded by an implicit psychological contract to follow the social norms of guanxi" (Chen and Chen, 2004). The norms include self-disclosure, dynamic reciprocity, and the long-term equity principle. The word "guan" in Chinese can in one sense be translated as referring to a "juncture", a "conjunctive point which connects otherwise separate entities" (Ibid). "Xi", on the other hand, in common usage means to tie up. Guanxi, therefore, as a noun implies a state in which things such as human beings are connected. Certainly guanxi can be defined at many different levels from many different perspectives (Hammond, Glen, 2004, Chen and Chen, 2004). However, the fundamental units of a guanxiwang, are the individual dyads of relationship within the group, and not necessarily the group entity itself (Chen and Chen, 2004). They go on to relate that these dyadic sentiments and obligations comprise the internal cohesion for guanxi. Guanxi relationships can be categorized by three levels of "closeness" or intimacy: family/kinship, familiar persons and strangers. Hwang (1987) delineates guanxi units based on whether they are socio-affective, mixed or purely instrumental. As Chen and Chen relates, it could be argued that these two rubrics are very consistent as relationships between family members are socio-affective while those with familiar persons are mixed, and those with strangers instrumental.

The basis for guanxi capital is highly particularistic and personal. The foundation basis for guanxi is a series interactions in which favors and information are exchanged over time, enmeshing individuals within networks of reciprocal obligation. Guanxi is not obvious nor easily identified and can only be perceived through interaction. Clearly, one of the bases for guanxi is the assumption of reciprocity, related to "bao" or social investment in others 
(Gold, 1985). "Xing", literally "trustworthiness" also plays a related and pivotal part in the assumption of reciprocity. It is based on two components, sincerity and ability. First and foremost trust develops when a party to a relationship is perceived as sincere in their intention to honor a guanxi obligation. Here relational proximity, whether an insider or outsider, plays an important part in the perception of trust. Only secondarily is trust based upon the perceived ability to perform (Chen, Chen 2004).

On the one hand one gains status and guanxi capital by demonstrating that one can get things done. Such instrumental bases for relationship are more pivotal with strangers (wa ren) (Hammond, Glen, 2004) than with family or acquaintances. On the other hand, relationships and obligations to insiders (zi ji ren), including a web of related parties by blood or friendship, transcend purely instrumental factors and embrace relational factors (Yang 1993). Trust under guanxi is a mix of instrumentalism and particularism, in which both trust and ability to perform reciprocal favors plays a part (Chen, Chen, 2004). As Gold (1985) states, add to this a heady mix of "renqing", or human feelings and empathy, and you end up with a complex concoction which tightly binds individuals within relational units.

With its origin in traditional clans, guanxi is woven into the tapestry of life in China (Park and Luo, 2001). Much of the literature refers to the influence of the teachings of Confucius on Chinese collective culture and guanxi in particular (Confucius, 1915, Redding, Wong, 1986, King, 1991). Although Confucius does not expressly use the term guanxi, the term "lun" is somewhat synonymous in its use in Confucian philosophy. Wu-lun refers to the fundamental tenet of Confucian teaching, that humans live in relationship to others. The five cardinal relationships of Confucianism include ruler/subject, father/son, husband/wife, elder brother/younger brother, and friend/friend (Chen, Chen, 2004). The second meaning of the term lun refers to social order, that order requires differentiation both hierarchically and horizontally. In the hierarchical relations relationships are characterized by unequal rights, obligations to those in higher positions within the hierarchy. The horizontal refers to those relationships differentiated not as much by unequal rights, but by increasing or decreasing closeness to self, with family blood ties predominating (Ibid). The final use of the term lun in Confucian philosophy refers to moral principles regarding interpersonal behavior. As Cheng (1990) proposes, Chinese traditions originating from Confucianism provide specific rules for each of the cardinal relationships and act as a glue to adhere society. As he suggests, Confucianism leads predictably to the tradition of honoring those closest to you.

One might also argue, in terms of the development of guanxi, that communism in China enhanced the role of utilitarian aspects of guanxi, such as "houmen" or corruption and the need for back-door favors. Gold (1985) argues that although the goal of the Chinese communist party was to snuff out personal and particularistic relational bases, and to substitute universal comradeship in their stead, it failed miserably. In fact in some ways it only enhanced the relational bases, as relations became extremely useful in an economy of scarcity. Yu, Chan and Ireland (2007) discuss how guanxi helped in procuring vital access to scarce goods and services. Although the basis for relations under Communism became somewhat less commoditized, nonetheless one could argue that the experience of Communism did not successfully destroy traditional particularistic personal relations but only reduced the commoditization of those relations to a degree. For example, non-material favors helped to navigate the highly unresponsive bureaucratic maze to "pull strings" and get things done under Communism.

Therefore, although Confucianism certainly could be argued to have formed the underlying foundation for guanxi, it is fairly clear that the development of certain facets of guanxi was facilitated by the need to cull favors and survive under communism (Guthrie, 1998). On the one hand, as Gold further relates, with the expanding role of the market and entrepreneurship in both the urban and rural areas, rising wages, increased production of consumer goods, and a new consumerist philosophy, the material basis for these traditional relationships has returned in force. However, one could also argue that the PRC, in its efforts to modernize, has in instigated broad based institutional changes leading away from this paternalism and particularistic relationships and toward a rational-legal system at the official level. And as it does, the importance of the need to "pull strings" has diminished (Ibid).

Guanxi, however, is multifaceted. Yang (1994) makes a distinction between guanxi and guanxi practice, between developing networks of social relations and using those relations to secure personal gain. Hong and Engestrom (2004) make a distinction between horizontal and vertical guanxi. Vertical guanxi stresses hierarchy along Confucian lines of authority, emphasizing respect and loyalty to a higher authority. Horizontal guanxi, on the 
other hand, focuses on developing strong communication channels, mutual respect, reciprocity, and long term mutual trust. A number of authors focus in on the informational transfer function of a guanxiwang (Ting-Toomey, 1988, Hammond, 2004). This is pivotal as a characteristic when one considers the virtual extension of guanxi networks onto the Internet.

Therefore, Chinese society is a relations centered world in which relationships are accorded great significance (Fahr, 1998). In fact, Chinese society is constructed around ways to promote collective social experiences among people. This is very consistent with two other salient and closely linked characteristics of traditional Chinese culture, collectivism and high context communication. Collectivism is one of the most widely discussed cultural variables across disciplines (Hofstede 1980, Hui and Triandis, 1986, Triandis, 1986, Ronen, Shenkar 1985, Tropenaar, 1983). In a collectivist society, members find self identity as members of the social system as opposed to from the individual. Emphasis is place on belonging to subgroups and maintaining one's primary allegiance to the collective. The sub-groups to which one belongs define ones identity and have impact on ones private life. Trust is placed not in individual initiative or decisions, but in the group decisions and consensus.

Schwartz (1990) proposes to us the caveat that collectivism does have different variants within and across cultures. Triandis, Chen and Chan (1998) distinguish between horizontal and vertical collectivists. Horizontal collectivists, while merging with the in group, do not subordinate. However, vertical collectivists will conform to group norms. For example, Chinese vertical collectivists supported the "marketizing" reforms issued by the Communist party, whereas horizontal collectivists resisted them (Wong, 2001). And as Chew and Putti (1995) note, the collectivist nature of the Chinese is expressed in loyalty to the family, whereas in Japan collectivism is reflected in a higher allegiance in the workplace. The Chinese culture ranks very low on individualism, lower than any other Asian country (ITIM, 2008). They also score very high on collectivism.

Many researchers within the literature confirm this finding (Hofstede, 1984, Lockett, 1988, Leung and Bond, 1984, Nevis 1983). Although some argue that the forces of modernization and globalization are cultivating a new spirit of individualism, albeit with a Chinese flavor (Ralston, 1995, Birnbaum-More, 1995, Yu, Chan, \& Ireland, 2007). On the other hand Gannon (2001) argues that a better characterization of Chinese culture would be neither individualist nor collectivist, but relational. $\mathrm{Li}$ (2000) refers to the Chinese variant of collectivism as familyoriented collectivism. Within the Chinese culture, relationships are taken very seriously.

In terms of communications, the Chinese culture is considered, as with other Asian cultures, to be high context (Hall, 1976, Gannon, 2001, Xia, 2006). Jen, one of the cardinal concepts of Confucian teachings is a collective concept which is comprised of various desirable virtues which should affect relations with others. These include self-restraint and self discipline, kindness to others, duty, loyalty, brotherly love, and to trust in interpersonal relations (Chen and Chung, 1993). Asians have been known to prefer indirect and ambiguous communication in contrast to the direct and clear communication preferred in low-context cultures (Cocroft \& Ting-Toomey, 1994). In addition, indirect communication is likely to appeal to Chinese because of the Confucian values absorbed within the culture, which emphasizes harmony and egalitarianism. A preferred communication style in Asian cultures in general and China in particular is to be careful to not take an explicit stand and to obscure one's position on an issue in order to help others save face. Meanings are to be inferred and less often articulated explicitly. In high context cultures the meanings are embedded within the context. As a result, the Chinese engage in indirect modes of communication in which where, how and by whom something is said is often even more important than the content of the message itself. People infer meanings from messages in light of their knowledge of the person and the context surrounding the message. It follows then that within these cultures close personal relationships characterized by guanxi are very important and extensive informational networks play an important part in the communication and interpretation of messages. Communication is facilitated by information which gives clues to meanings imbedded in context.

\section{THE CASE: BBS IN CHINA}

China currently has the world's largest online population. And the government has dedicated a substantial amount of expenditures to developing and improving telecommunications infrastructure. As of 2009 China has 384 million users and that at only a 28.9 rate of penetration (CNNIC, 2009). The fastest growth has occurred in online 
business transactions (up 68\% over 2008) and online payments (up $80.9 \%$ over 2008). Penetration is still low compared to the US, Japan and Korea, which register penetration rates of 74.1, 75.5, and 77.3 respectively. China already has the largest population of mobile phone users. It is in this area that China has seen the lion's share of growth in internet access, which has lowered the threshold for access for a large number of users. As a result, the growth rate of access via mobile phone was $98.3 \%$ in 2009 compared to $42.4 \%$ for laptops and $5.8 \%$ for desktop computers.

One very interesting phenomenon is the popularity and persistence of the use of what many in the West consider old school, electronic bulletin board systems. A BBS might be defined as a computer and associated software which provides a database for electronic messages, split into topic groups (Liu and Dimitrova, 2007). In the past this would take place over an analog phone line, although web-based applications are currently available. Remote users can upload images, download software and data, play games, read news, write articles and reply to posts on a variety of subjects. The first BBS in China was set up in 1991 and the use and popularity of BBS has increased rapidly since that time. As opposed to SNS (social networking sites) which are networking centric and real-time, BBS interaction is both topic-centric and asynchronous, a sort of opinion exchange platform. It provides a bottom up, many to many platform which guarantees a diversity of voices (Jin, 2008). BBS are ever changing, with continuously updated news and information. They are also open and anonymous. Administrators do not have the power to arbitrarily remove or modify posts, as they do with blogs and SNS. And users can post with the knowledge that their identities will not be revealed, and privacy protected. Posts can be made by anyone, and there is no limit on the length of the post.

The popularity of BBS in China is truly an internet phenomenon of note (Wang, 2009, Lu, 2009, Jin, 2008, China Vortex, 2008, Web 2.0 Asia, 2008). For example, by the end of June, 2009, China's BBS community websites reached an average of approximately 44 million unique visitors, an increase of $68.8 \%$ over 2008 (Fu, 2009). Of the staggering facts, one is that $98 \%$ of online BBS users are active members having published articles, or replied to posts and polls. And 13.8\% spend $1 / 3$ of a day on BBS forums. Almost half of all net-citizens spend over four hours a day on BBS forums. BBS forums are popular among Chinese for doing product related searches. In fact in 2008 47\% BBS users bought products directly from the BBS site (Tech Radar, 2008). As an indication of their popularly, in a 2008 study of reader responses to the top 100 news stories on a SINA.com's BBS, an online news service, identified 30,000 reader responses a day. BBS systems in China have been registering a huge 1.6 billion daily page views and 10 million posts (Lin, 2008). BBS users in China tend to be more mature with an average age between 20 and 40 years old. They are educated, from various professional backgrounds.

Students at Chinese Universities are major users of BBS. In the mid 1990s the Chinese government constructed internet infrastructure on university campuses, which made college student the first adopters of the internet in China, including BBS. More than 130 BBS at more than 80 universities had been established by 2007 (Jin, 2008). Most every university in China has its own BBS which their students cherish and to which students maintain fierce loyalty, defending the reputation and purity of their piece of virtual real estate. Students at Chinese universities are avid users of BBS, spending several hours a day chatting, posting, reading and joining discussions. As Jin states, BBS become extremely important forums, collective companions containing all aspects of campus life and exert a critical impact on their university life (Ibid.). They become forums for discussions, making friends, sharing experiences, expressing, in relative anonymity, opinions on academic subjects, chatting regarding interests or simply be connected.

\section{BBS: AS VIRTUAL THIRD SPACES/NASCENT PUBLIC SPHERES/ONLINE COMMUNITIES}

One might argue that BBS in China might be conceived of as virtual third spaces in which a nascent civil society does its business of creating a conversation about those things most important to them, in an environment that feels safer, and has fewer constraints than within formal society. As Ray Oldenburg notes $(1989,2000)$ third places "exist on neutral ground and serve to level their guests to a condition of social equality. Within these spaces conversation is the primary activity". He goes on to say that third places, though offering radically different environments from home, are quite similar to home in terms of the psychological comfort and support one receives there. BBS could be thought of as virtual third spaces as they are used in China. BBS in China clearly allow users to explore mutual interests, set collective agendas, affiliate and build virtual communities outside of and in many 
ways free from the controls of a society and government which places numerous constraints on behavior. Certainly, as long as China labors under a repressive regime, all too cognizant of the danger of too much freedom, the discourse in this virtual third space will be constrained and will only take place within the limits set. However, at times this has clearly gone beyond what the regime would like.

For example, in 2003, the BBS had enormous impact in the case of a young graduate of Wuhan Academy of Science and Technology, Sun Zhigang, who was detained by police for failing to present a valid ID. Sun was subsequently beaten to death while in custody. At first the story got scant attention as a result of an article in traditional media. However, the story generated a storm of protest and discussion within online communities on BBS. And, interestingly enough, the pressure generated by public protest on BBS was instrumental in leading to a change in legislation. The ability of BBS to generate issue focused community "buzz" is certainly a concern for the regime. The BBS are also receptive and effective vehicles for the "angry Chinese" or "fenqing" to express their distrust of the official media (Vortex China, 2008). These "angry Chinese" are self-organized on BBS, number in the millions, are lithe and disappear quickly into anonymity, distrust officials, are a kind of "issue focused flash mob" (ibid).

One has to consider that as economic reforms progress and the forces of modernization wend their way into the consciousness and behavior of the Chinese population, a logical disconnect has become all too apparent between official ideology and traditional culture in contrast with modern values celebrating consumption, pragmatism, individualism and material enrichment (Dong, 2003). Young Chinese 20-40 are the demographic who utilize BBS the most. And it is this demographic which is trying to make sense of their lives while facing a number of critical conflicts between the myriad of political, social and cultural constraints in traditional society and the forces and values of modernization.

BBS are attractive for a number of reasons to this mass of young Chinese. First, the communities of BBS are relatively free, equal, anonymous and post-modern (Dong, 2003). It is a place where people meet face to face virtually but void of the social constraints of real life face to face meetings. For example, one does not have to worry as much about losing face on BBS forums, and can speak more freely and frankly, in a more low-context fashion. And the rich contextual indicators regarding rank, age, relations do not exist in this anonymous cybercultural community, which makes relationships based more on equality and less on hierarchy.

Next, they are places where community is developed and connections made. One could argue that it is a preeminent place for guanxi connections, but focusing more on the social relational facet of guanxi as opposed to instrumental guanxi practice. As Hong and Engestrom (2004) relate, the old paternalistic focus of guanxi is transforming to broader social networking in the face of the forces of modernization. Community relations also appear less based on vertical relations of power and authority, status and prestige and more on horizontal establishment of social relations based on equality and common interests. Traditional guanxi is based on concentric relations, with close family members at the core and more distant acquaintances at the periphery. In Confucian philosophy, "Wu Lun" is based on five cardinal relationships, the first being ruler/subject, then father/son, husband/wife, brothers, and between friends. As one moves away from the center the degree of trust diminishes. But within the context of virtual guanxi as witnessed in the BBS context, there is a flattening of hierarchy. And, one might argue, real geographical proximity is being replaced by virtual relational proximity based on common interests and common membership on BBS.

The trust necessary to grease the wheels of virtual guanxi is afforded through the operations of the BBS. An example is the selection mechanism for posts on Chinese BBS which drives traffic to certain sites. On the average BBS main page is an eye-catching display heralding the current top 10 posts based on click rate and number of posts. For example, Tianya BBS, a top BBS in China, might have a banner "Recommended hot issues" posted on their main page. When a post rises to the top 10 this generates viral interest, exponential attention from the entire BBS community (Jin, 2008). The Chinese model is skewed toward mass interest, whereas in the United States, collective wisdom as evidenced by the most visited site has little impact on user preference. Also, Chinese net citizens tend to trust what they find, but this trust is based on a number of things including number of replies, number of times the post has been viewed, and how many times it has been tagged as a good post. Over half show their support for a post by replying to the original post. And over one fourth would even repost a trusted post to 
other BBS forums $(\mathrm{Fu}, 2009)$. In traditional guanxi, relational proximity (family first) is a major factor of trust within a guanxiwang (Chen and Chen, 2004). However, as noted above, one could argue that membership on BBS creates this virtual family of like interests therefore engendering trust within the community. Therefore collective wisdom serves as a major element for eliciting trust on BBS in a characteristically guanxi fashion. Finally, there is the trust garnered by trusted experts which are created in BBS communities. The Chinese word "Da'rens", roughly translated "people who know how to do something" refers to the phenomena of online experts who are touted to have a high degree of skill or knowledge or knowledge in a particular subject like music, cosmetics or computers. For example, Arora, became a very popular make-up cosmetics Da'ren on BBS and subsequently launched a blog in the mega-portal Sina.com (Wang, 2009). Again, this is very consistent with Confucian philosophy and the reverence for education and seeking those who know something.

One might maintain the anonymity of the BBS community "liberates individual users from a variety of cultural and social constraints in many ways" cultivating individualistic mindsets (Jin, 2008). However, the BBS community is still essentially a collective and privileges a collective identity. This virtual third space is a place where collective and individual identities interact in a dynamic way, to fashion new social norms, values and behaviors, as the modern and traditional find themselves occupying the same psychic space in China (Chinese Identities in the Internet Age, 2010). But these BBS communities are still quintessentially collective and Chinese. This is characterized in a number of BBS behaviors in China including "Flocking conformity" and "human flesh search engine". Flocking conformity refers to how Chinese BBSers swarm around popular topics in ways which contrasts with their western counterparts. This leads to a cluster of interests around popular topics. This creates a virtual "buzz" about popular posts leading to collective interest in a subject. Obviously this can lead to some less savory behavior. "Ren rou sou suo yin qin" used to describe the behavior of BBS communities where masses of users mobilize to search out the truth, uncover facts, and expose them to the public. It involves a relentless pursuit of truth, many times bordering on collective cyber-gossip. This is easy to understand considering that these Chinese net-citizens are not only collective in cultural values and educated but many are also intellectually under-employed (Ibid, 2008).

Also, although these communities could be characterized more by horizontal than by vertical relationships certainly Chinese virtual BBS communities do have salient elements of organization and hierarchy. First, Chinese BBS are either comprehensive or specialized by topic. The first difference between the United States BBS and those of China is the proliferation of dense comprehensive sites with a wide spectrum of topics under one roof (Jin, 2008). In the US, users prefer specialized BBS to mass one. Efforts to consolidate these highly specialized and autonomous forums have in the past failed (AOL). These diverse comprehensive BBS forums in China offer a rich context for the expression of diverse voices on a multiplicity of topics. BBS are then divided into sub-forums, by user interest, and then sub-categorized by discussion boards on specific topics. A "banzhu", or moderator/administrator supervises each board, cleaning posts, tagging useful articles, and mediating conflicts. The hierarchy of a BBS in China then differentiates between these moderators and average users, experienced vs. inexperienced users, those socially connected (recognize usernames and keep in close contact with other users) and not connected.

There is also on online ranking system applied in BBS for users. ID ranks are assigned based upon a number of criteria including hours online, login time, and total articles posted (Ibid). The ranking system is then customized by the BBS. For example, LilyBBS assigns "military", "flower" or "common" ranks. And then each is subdivided into a hierarchy of ranks. Military rank has soldier, lieutenant, captain, general, etc. Flower rank has unknown flower, flower spirit, lily fairy, etc. And the BBS hierarchy is effective at motivating using behavior in search of status, to become intimately involved in activities on their BBS such as posting articles in order to garner points and get promoted. This in term motivates the behavior known as "Gua zhan", which can be translated as "hanging on to sites" (Ibid) in order to rack up points, and "guan shi" or "pouring water" in which a user posts voluminous numbers of articles to move up the ranks. Finally, there are also experts in the hierarchy, Da'rens, whose virtual guanxi capital is a result of demonstrated expert knowledge, the ability to deliver accurate and useful information on a topic. Although it appears as though that this hierarchy may be more achievement oriented than ascriptive and therefore different from the bases for traditional guanxi, one could argue that it has many similarities with one of the elements of "Xing" or trustworthiness, central to guanxi. Xing values not only intention, but perceived or demonstrated ability to perform a task. 


\section{CONCLUSIONS: ONLY THE BEGINNING}

China is a superlative in so many ways. Everyone is talking about China. It is a country with a rich and diverse history and culture, home to approximately one fifth of the world's population. Although still a repressive communist totalitarian regime, remarkably its economy is rapidly transitioning away from central planning and its government has been selectively liberated the economy and the country is facing dramatic shocks as its traditional culture comes face to face with the forces of modernization as well as the attendant new values such as consumerism, individualism, capitalism, and materialism. As part of this plan, the government has embraced technology. China currently has the world's largest online population. But Pandora may be escaping from the box. As the dizzying pace of change continues, the Internet is leading the way, and accelerating that change as a virtual "third space" and nascent public sphere.

This particular piece of research explores the possibility that BBS's are a virtual third space in which we find traditional social constructs in China being challenged and modified in important ways. Specifically the research underlying this paper examined two hypotheses. The first was that an analysis of the interaction, operations and structure within these social spaces (BBS) might lead one to consider whether or not Guanxi, the relational glue which binds Chinese society together as well as other related cultural values and behaviors, are not being updated and modified in critical ways within these virtual third spaces. The second hypothesis examined proposed that Guanxi may be bifurcating within the virtual societies of the BBS, where the shared collective experiences of "social networking" of Guanxi has split from the "utilitarian reciprocal obligation" of "houmen" and guanxi practice.

The research articulated four interrelated characteristics of Chinese culture relevant to our topic: Guanxi, Confucianism, collectivism and high contextuality. The analysis proposed that the social/relational and hierarchical values of Confucianism, as well as the experience of communism contributed to the development of guanxi. Guanxi was proposed as the highly particularistic and personal web of dyadic relations characterized by reciprocal obligations that binds Asian Chinese society together. We propose that Guanxi is multifaceted, consisting of both social networking facets as well as instrumental "guanxi practice". Trust under guanxi is a mix of instrumentalism and particularism, in which both trust and ability to perform reciprocal favors is critical. Chinese society is constructed around ways to promote collective social experiences among people. This is very consistent with two other salient and closely linked characteristics of traditional Chinese culture, collectivism and high context communication. Within these cultures close personal relationships characterized by guanxi are very important and extensive informational networks play an important part in the communication and interpretation of messages.

The popularity of BBS in China is truly an internet phenomenon of note. BBS systems in China have been registering a voluminous 1.6 billion daily page views and 10 million posts. BBS users in China tend to be more young and more mature with an average age between 20 and 40 years old. They are educated, from various professional backgrounds. Students at Chinese Universities are major users of BBS. BBS interaction is topiccentric and asynchronous, a sort of opinion exchange platform. It provides a bottom up, many to many platform which guarantees a diversity of voices. BBS are ever changing, with continuously updated news and information.

One might argue that BBS in China might be conceived of as virtual third spaces in which a nascent civil society does its business of creating a conversation about those things most important to them, in an environment that feels safer, and has fewer constraints than within formal society. BBS in China facilitate mutual interests, setting collective agendas, affiliating and building virtual communities outside of and in many ways free from the controls of a society and government which places numerous constraints on behavior. Sometimes even out of the control of the governmental, one which has even had an influence on government policy. We also proposed that BBS communities certainly create an environment which nurtures individualist values. Free, egalitarian, anonymous and post-modern nature of BBS make them highly attractive to younger "seekers", cause in the vice between traditional values and constraints and modern values such as consumerism, expressing personal opinions, materialism, individualism and capitalism. It is a place where people meet face to face virtually but void of the social constraints of real life face to face meetings, free of the rich contextual indicators regarding rank, and age which makes relationships based more on equality and less on hierarchy. 
One the other hand, they are still collective places, where community is developed and connections made. One could argue that it is a preeminent place for guanxi connections, but focusing more on the social relational facet of guanxi as opposed to instrumental guanxi practice. Community relations also appear less based on vertical relations of power and authority, status and prestige and more on horizontal establishment of social relations based on equality and common interests. However, within the context of virtual guanxi as witnessed in the BBS context, there is a flattening of hierarchy. Geographical proximity is being replaced by virtual relational proximity based on common interests and common membership on BBS. A number of behaviors which can be witnessed on BBS, including flocking conformity, "ren rou sou suo yin qin" (human flesh search engine), popularity based on "buzz" all are attest to the importation of collective behaviors from traditional society, but modified within the BBS context.

Finally, although BBS are less based on traditional vertical relations, they are not devoid of structure and hierarchy. Different from in the West, comprehensive sites populate the BBS world, in which a wide variaty of topics are under one roof. These are then divided into sub-forums, by user interest, and then sub-categorized by discussion boards on specific topics. There is also on online ranking system applied in BBS for users. It is also interesting how the BBS hierarchy is effective at motivating using behavior in search of status such as "Gua zhan", "hanging on to sites" in order to rack up points, and "guan shi" or "pouring water" where users post multiple articles to earn points to move up in rank. Finally, there are also experts in the hierarchy, Da'rens, who are something of virtual "oracles", trusted for their knowledge in a certain topical area of interest.

The operations of the BBS themselves have developed their own trust framework, a characteristic essential for guanxi. First of all is the selection mechanism which drives traffic to posts. This includes eye catching top ten banners heralding the current top 10 posts based on click rate and number of posts. Chinese model is skewed toward mass interest, whereas in the United States, collective wisdom as evidenced by the most visited site has little impact on user preference. Chinese net citizens tend to trust what they find, but this trust is based on a number of things including number of replies, number of times the post has been viewed, and how many times it has been tagged as a good post. The BBS also creates the mechanism for "relational proximity" by creating a virtual family of like interests therefore engendering trust within the community. Finally, there is the trust garnered by trusted experts, Da'rens, which are created in BBS communities, consistent with Confucian philosophy and the reverence for education and seeking those who know something.

Therefore, we have tentative support for both of our hypothesis. It appears a strong argument can be made that BBS in China are quintessentially Chinese, and indeed are becoming virtual third spaces, nascent public forums, virtual communities. And the interaction, operations, and structure of these communities is a place in which traditional culture and modernization are dynamically interacting to update/modify Guanxi as well as other related cultural values and practices. Secondly, there appears to be adequate evidence that Guanxi is bifurcating, and that the relational social networking facets are being highlighting within BBS, while the utilitarian aspects of guanxi practice and "houmen" are being marginalized.

However, it is clear that further research is necessary beyond this admittedly cursory rumination of secondary data and the current literature. This authors hopes that the thinking and direction of this paper will motivate a deeper examination of a subject which clearly has such incredible implications for scholars and practitioners. Finally, a secondary question, beyond the scope of this research, is how this new virtual culture may spill over and lead to modification of real world norms of interaction within China and what the repercussions of those changes on Chinese culture in the long term.

\section{AUTHOR INFORMATION}

Dr. Peter L. Banfe, Associate Professor of International Business at the James F. Dicke College of Business at Ohio Northern University. Received MSci from the London School of Economics and PhD from The George Washington University in International Political Economy. 15 years experience in government and private industry in exporting and finance, and in government regulation (ExIm Bank, Federal Home Loan Bank). Currently run small export/Import firm. Research interests and publications include culture, the internet and virtual communications in China, the China market, service learning and experiential pedagogy especially related to teaching students to be globally aware and attain a global acumen. 


\section{BIBLIOGRAPHY}

1. BBC News, (2010, January 21). China Shows Strong Growth in 2009. Retrieved May 2010, from http://news.bbc.co.uk/2/hi/8471613.stm

2. Birnbaum-More, P. H. Wong, G. Y. Y. \& Olve, N. (1995). Acquisition of Managerial Values in the People's Republic of China and Hong Kong. Journal of Cross-Cultural Psychology, 26 (3), 255-275.

3. Chen, G.-M., \& Chung, J. (1993). The Impact of Confucianism on Organizational Communication. Communication Quarterly, 93-105.

4. Chen, X., Chen, C. (2004). On the intricacies of the Chinese guanxi: A process model of guanxi development. Asia Journal of Management, 21, 305-324.

5. Cheng, O. (1990). Understanding the culture and behavior of east Asians: A Confucian perspective. Australian and New Zealand Journal of Psychiatry, 24, 510-515.

6. Chew, I. K. H., Putti, J. (1995). Relationship on work-related values of Singaporean and Japanese managers in Singapore. Human Relations, 48 (10), 1149-1170.

7. The China Vortex, What Tibet and Carrefour Can Teach Us About the Chinese Internet. (2008, May 9). Retrieved May 2010, from The China Vortex: http://www.chinavortex.com/2008/05/what-tibet-andcarrefour-can-teach-us-about-the-chinese-internet/

8. Cocroft, B., \& Ting-Toomey, S. (1994). Facework in Japan and the United States. International Journal of Intercultural Relations, 18, 469-506.

9. Confucius (1915). The Ethics of Confucius. New York: Putnam.

10. Dong, D. , 2003-05-27 "Resistance within Contexts:A Study of University BBS Youth Culture in China" Paper presented at the annual meeting of the International Communication Association, Marriott Hotel, San Diego, CA

11. Fu, R. (2009, November 10). Brief Guide on China Online BBS Community. Retrieved May 2010, from ChinaInternetWatch.com: http://www.chinainternetwatch.com/369/china-bbs-forums/

12. Chinese Identities in the Internet Age. Retrieved May 2010, from China BBS Research: http://www.chinabbsresearch.de/

13. Gannon, M. J. (2001). Understanding Global Cultures: Metaphorical Journeys Through 28 Nation. Thousand Oaks, CA: Sage Publications

14. Gold, T. B. (1985). After comradeship: Personal relations in China since the Cultural Revolution. The China Quarterly, 104, 657-675.

15. Hall, E. (1976). Beyond Culture. Garden City, NY: Anchor/Doubleday.

16. Guthrie, D. (1998). The Declining Significance of Guanxi in China's Economic Transition. Cambridge University Press.

17. Hammond, S. C., Lowell, M. G. (2004), The ancient practice of Chinese social networking: Guanxi and social network theory. E:CO, $6(1,2), 24-31$.

18. Hofstede, G. (1980). Motivation, leadership, and organization: Do American theories apply abroad. Organizational Dynamics, 9 (1), 42-63.

19. Hofstede, G. (1984). The culture relativity of the quality of life concept. Academy of Management Review, 9 (3), 389-398.

20. Hong, J. \& Engestrom, Y. (2004). Changing Principles of Communication between Chinese Managers and Workers. Management Communication Quarterly, 552-585.

21. Hui, C. H., Triandis, H. C. (1986). Individualism-Collectivism: A Study of Cross-Cultural Perspectives. Lincoln: Nebraska University Press.

22. Hwang, K. K. (1987). Face and favor: The Chinese power game. American Journal of Sociology, 92, 944-974.

23. ITIM International (ITIM) (2008). Geert Hofstede Cultural Dimensions, China. Retrieved June 4, 2008 from http://www.geert-hofstede.com/hofstede china.shtml

24. Jiing-Lih Farh, et al. (1998). The Influence of Relational Demography and Guanxi: The Chinese Case. Organization Science , 471-488.

25. Jin, L. (2008). Chinese Online BBS Sphere: What BBS Has Brought to China. Massachusets Institute of Technology.

26. Katz, J. E., Aakhus, M. A. (eds.) (2002). Perpetual Contact: Mobile Communication, Private Talk, Public Performance. Cambridge: Cambridge University Press. 
27. Katz, J. E. (ed.) (2003) Machines that Become Us: The Social Context of Personal Communication Technology. New Brunswick, NJ: Transaction Publishers.

28. Katz, J. E., Aakhus, M. A., Kim, H. D., \& Turner, M. (2003). Cross-cultural Comparison of ICTs. In L. Fortunati, J. Katz, and R. Riccini (eds.), Mediating the Human Body: Technology, Communication, and Fashion, Mahwah, NJ: Lawrence Erlbaum.

29. King, A. Y. (1991). Kuan-his and network building: A sociological interpretation. Daedalus, 120, 63-84.

30. Leung, K., Bond, M. H. (1984). The Impact of Cultural Collectivism on Reward Allocation. Journal of Personality, and Social Psychology, 47, 793-804.

31. Li, J., Lam, K., Fu, P. P. (2000). Family oriented collectivism and its effects on firm performance: A comparison between overseas Chinese and foreign firms in China. The International Journal of Organizational Analysis, 8 (4), 364-379.

32. Liu, V. Y., \& Dimitrova, D. (2007). The Uses of and Gratifications Derived from Bulletin Board Systems (BBS) in Chinese Youth. China Media Research .

33. Lockett, M. (1988). Culture and the problem of Chinese management. Organization Studies, 9 (3), $475-$ 496.

34. Lu, G. (2008, January 17). Chinese BBS - The Undiscovered Phenomenon in Chinese Internet. Retrieved May 2010, from Mobinode.com: http://www.mobinode.com/2008/01/17/chinese-bbs-the-undiscoveredphenomenon-in-chinese-internet/

35. Nevis, B.C. (1983). Using an American perspective in understanding another culture: Toward a hierarchy of needs for the People's Republic of China. The Journal of Applied Behavioral Science, 19 (3), $249-264$.

36. Ralston, D. A., Gustafson, D. J., Terpstra, R. H., \& Holt, D. H. (1995). Pre-post Tiananmen Square; Changing values of Chinese managers. Asia Pacific Journal of Management, 12 (1), 1-20.

37. Oldenburg, Ray (1989). The Great Good Place: Cafes, Coffee Shops, Community Centers, Beauty Parlors, General Stores, Bars, Hangouts, and How They Get You Through the Day. New York: Paragon House.

38. Oldenburg, Ray (2000). Celebrating the Third Place: Inspiring Stories about the "Great Good Places" at the Heart of Our Communities. New York: Marlowe \& Company.

39. Park, S. H., Luo, Y.. (2001). Guanxi and Organizational Dynamics: Organizational Networking in Chinese Firms. John Wiley \& Sons.

40. Mathias, I. (2009, February 9). China's Second Leap Forward, Retrieved May 2010, from Daily Reckoning: http://dailyreckoning.com/chinas-second-forward/

41. BBC News, (2010, January 21). China Shows Strong Growth in 2009 Retrieved May 2010, from http://news.bbc.co.uk/2/hi/8471613.stm

42. Redding, G., Wong, G. Y. Y. (1986). The psychology of Chinese organizational behavior. In M. H. Bond (eds.), The Psychology of the Chinese People, New York: Oxford University Press.

43. Ronen, S. \& Shenkar, O. (1985). Clustering countries on attitudinal dimensions: A review and synthesis. Academy of Management Review, 10, 435-454.

44. Schwartz, S.H. (1990). Individualism -collectivism: Critique and proposed refinements. Journal of CrossCultural Psychology, 21 (2), 139-157.

45. (2009). Statistical Survey Report on Internet Development in China. China Internet Network Information Center.

46. Tech Radar, So where's China in the world of Social networking Sites - Facebook, MySpace. (2008, May 9). Retrieved May 2010, Tech Radar: http://techradar1.wordpress.com/2008/01/17/so-wheres-china-in-theworld-of-facebook-myspace/

47. Ting-Toomey, S. (1988). Intercultural conflict styles: A face negotiation theory. In Y. Y. Kim \& W. B. Gudykunst (eds.), Theories in intercultural communications, Newbury Park: Sage.

48. Triandis, H. C. (1995). Individualism and Collectivism. Boulder, CO: Westview Press.

49. Triandis, H. C., Chen, X. P., \& Chan, D. K. (1998). Scenarios for the measurement of collectivism and individualism. Journal of Cross Cultural Psychology, 29 (2), 275-289.

50. Trompenaars, F. (1993). Riding the Waves of Culture. London: Brealey.

51. Yang, K. S. (1993). Chinese social orientation: A social dynamic perspective. In K. S. Yang \& A. P. Yu (eds.), Chinese Psychology and Behavior - Theory and Methodology, Taipei: Kui Kwan Publishing.

52. Yang, M. (1994). Gifts, Favors and Banquets: The Art of Social Relationships in China, Ithaca, NY: Cornell University Press 
53. Yu, L., Chan, C., \& Ireland, C. (2007). China's New Culture of Cool: Understanding the World's Fastest Growing Market. New Riders Publishing.

54. Wang, W. (2009, November). Don't Assume China Mimics US-Style Social Media. Retrieved May 2010, from DevComments.com: http://www.devcomments.com/Don-t-Assume-China-Mimics-US-Style-SocialMedia-i4939.htm

55. Web 2.0 Asia, Is the Chinese BBS really the future of social media? (2008, May 10). Retrieved May 2010, from Web 2.0 Asia: http://www.web20asia.com/275

56. Wong, E. Y. (2001). The Chinese at work: Collectivism or individualism?. Hong Kong Institute of Business Studies, February, 2001, working paper 040-001.

57. Xia, Y. (2006). Cultural Values, Communications Styles, and Use of Mobile Communications in China. China Media Research, 2 (2), 64-73. 